\title{
COGESTÃO EM RESERVA EXTRATIVISTA NA AMAZÔNIA: INOVAÇÃO SOCIAL PARA SUSTENTABILIDADE? O CASO DA RESEX TERRA GRANDE DO PRACUÚBA, ESTADO DO PARÁ
}

\section{Ynis Cristine de S. M. L. Ferreira}

Contadora, Especialista em Informação Ambiental (NUMA/UFPA), Mestra Gestão dos Recursos Naturais e Desenvolvimento Local na Amazônia (NUMA/UFPA), Doutoranda em Administração (UNAMA), Professora da Universidade Federal Rural da Amazônia (UFRA).

\section{Mário Vasconcellos Sobrinho}

Economista, Mestre em Planejamento do Desenvolvimento (NAEA/UFPA), PhD em Estudos do Desenvolvimento (CDS, Swansea University), Pós-doutor em Administração Pública e Governo (EAESP/FGV). Professor titular da Universidade da Amazônia (UNAMA), Programa de Pós-Graduação em Administração (PPAD); Professor do Programa de Pós-graduação em Gestão de Recursos Naturais e Desenvolvimento Local na Amazônia (PPGEDAM) do Núcleo de Meio Ambiente (NUMA) da Universidade Federal do Pará (UFPA).

\section{Ana Maria de Albuquerque Vasconcellos}

Cientista Social, Mestra em Planejamento do Desenvolvimento (NAEA/UFPA), PhD em Estudos do Desenvolvimento (CDS, Swansea University), Professora titular da Universidade da Amazônia (UNAMA) onde leciona no Programa de Pós-graduação em Administração (PPAD).

\section{Resumo}

$\mathrm{O}$ artigo discute a relação entre cogestão e sustentabilidade em propriedade comunal na Amazônia. De forma específica, debate como ocorre o processo de cogestão enquanto modelo de gestão para a sustentabilidade em uma Reserva Extrativista (RESEX). Tem-se como questões norteadoras: como ocorre a cogestão dos recursos comuns em RESEX? A cogestão pode ser entendida como uma inovação social para a gestão de recursos comuns em áreas protegidas? O estudo está alicerçado na teoria dos recursos comuns, "Common Pool Resources" (OSTROM, 1990) e no campo teórico em construção denominado Gestão Social (CANÇADO; PEREIRA; TENÓRIO, 2015). Entretanto, são utilizados como conceitos-chaves a cogestão e a coprodução para o bem comum. Metodologicamente, trata-se de um estudo de caso. Elegeu-se a RESEX Terra Grande do Pracuúba - Comunidade São José do Abacatal Turé, uma propriedade de estrutura comunal. Esta RESEX localiza-se no município de Curralinho, no estado do Pará, Amazônia brasileira. O estudo mostra que a cogestão como estratégia efetiva de gestão sustentável de recursos comuns é limitado em seu escopo e resultados. Embora a cogestão possa ser entendida como uma inovação social para a gestão e sustentabilidade de recursos comuns em áreas protegidas, este conceito advém de relações históricas estabelecidas intra-comunidades que não estão necessariamente presentes em RESEX.

Palavras-chave: Cogestão. Reserva extrativista. Inovação Social. Sustentabilidade. 


\title{
CO-MANAGEMENT IN EXTRACTIVE RESERVE IN THE AMAZON: SOCIAL INNOVATION FOR SUSTAINABILITY? THE CASE OF EXTRACTIVE RESERVE TERRA GRANDE DO PRACUÚBA, STATE OF PARÁ
}

\begin{abstract}
The paper discusses the relationship between co-management and sustainability in communal ownership in Amazon. Specifically, it debates how the co-management process as a management pattern for sustainability arises in an Extractive Reserve (RESEX). The paper questions are: how does co-management of common resources in RESEX happens in practice? Can the co-management be understood as a social innovation for common resources management in protected areas? The study is based on the theory of "Common Pool Resources" (OSTROM, 1990) and on the building theory of Social Management (CANCADO; PEREIRA; TENÓRIO, 2015). However, the concepts of co-management and co-production for common good are also used. Methodologically, the paper is based on a case study. The research chose for analysis the RESEX called Terra Grande do Pracuúba, Community of São José do Abacatal, a communal ownership. This RESEX is located in the municipality of Curralinho, in Pará State, Brazilian Amazon. The study shows that co-management as an effective strategy for sustainable management of common resources is limited in its scope and results. Although the co-management can be understood as a social innovation for common resources management and sustainability in protected areas, this concept comes from historical relationships established intra-communities that are not necessarily present in RESEX
\end{abstract}

Keywords

Co-management. Extractive reserve. Social innovation. Sustainability.

\section{INTRODUÇÃO}

Unidades de Conservação (UC) são espaços territoriais que possuem recursos ambientais com características naturais relevantes, incluindo as águas jurisdicionais (BRASIL, 2000, p. 1). De acordo com o Sistema Nacional de Unidades de Conservação (SNUC) (BRASIL, 2000), as UC são classificadas em públicas e privadas e qualificadas em dois grupos de categorias distintas: Proteção Integral e Uso Sustentável. Estes territórios são necessariamente instituídos pelo Poder Público com objetivos de conservação dos recursos bióticos e abióticos. Para sua adequada gestão, as UC possuem limites geograficamente definidos e devem seguir um regime especial de administração (BRASIL, 2000).

O objetivo das UC de Proteção Integral é a preservação total da natureza, permitindo-se somente o uso indireto dos recursos naturais existentes no território. As UC de Uso Sustentável, por sua vez, tem como objetivo a conservação da natureza em consonância com o uso sustentável de parcela dos seus recursos naturais para fins econômicos (BRASIL, 2000). As Reservas Extrativistas (RESEX) são uma subcategoria do grupo de Unidades de Conservação de Uso Sustentável. 
Em termos de gestão, por legislação, as RESEX devem ser estruturadas com a constituição de um conselho gestor que atua como um espaço de consulta ou deliberação. A finalidade maior do conselho é traçar diretrizes e auxiliar o administrador da UC na gestão do território considerando, sobretudo, a integração da população tradicional e as ações realizadas no seu entorno. O conselho gestor é o espaço formal e instância para a gestão participativa na administração da RESEX (BRASIL, 2015). O funcionamento desse espaço sugere a existência de um arcabouço institucional formado por normas e regras formais e informais (OSTROM, 1999). No caso específico das RESEX, os conselhos focam-se na gestão dos recursos comuns sob um regime especial de administração que se relaciona com o manejo de recursos socioecológicos (MCGINNIS; OSTRON, 2010) comunais de custódia pública. De fato, a gestão das RESEX assumem pressupostos de gestão compartilhada dos recursos comuns por diversos atores com convergentes e divergentes interesses que neste trabalho são assumidos como cogestão. Este conceito traz uma série de princípios que se aproximam com o que estatui o campo teórico da gestão social (CANÇADO; PEREIRA; TENÓRIO, 2015) em que a participação, o diálogo e o interesse bem compreendido são peças fundamentais para a boa governança de um território.

Sob outra perspectiva, Cole; Epstein; McGinnis (2014), apoiando-se no SocialEcological Sistems (SES) pensado por Ostrom (MCGINNIS; OSTRON, 2010), analisam a gestão de espaços comunais e propõem uma metodologia de análise do processo de gestão denominado Institutional Analysis and Development (IAD). Este se propõe a compreender a os padrões de comportamento e os resultados observados na gestão dos espaços comunais a partir de uma visão implicitamente dinâmica dos processos políticos existentes no território. Portanto, tem-se, assim, tanto aspectos sociais quanto políticos que influenciam diretamente na cogestão de um território de propriedade comunal (FEARNSIDE apud DIEGUES, 2001) a exemplo de uma RESEX.

No contexto da complexidade que envolve características sociais e políticas para a gestão de um território de propriedade comunal é que se questiona: como ocorre a cogestão dos recursos comuns em RESEX? A cogestão pode ser entendida como uma inovação social para a gestão de recursos comuns em áreas protegidas?

Metodologicamente, a pesquisa da qual este artigo é derivado tomou como método o estudo de caso. Elegeu-se a RESEX Terra Grande do Pracuúba - Comunidade São José do Abacatal Turé, uma propriedade de estrutura comunal localizada no município de Curralinho, 
no estado do Pará, Amazônia brasileira. Realizou-se pesquisa exploratória para compreender o processo de cogestão como modelo para a sustentabilidade de um sistema socioecológico baseado no extrativismo. Assim, tem-se como unidade de análise a Comunidade São José do Abacatal Turé. Utilizou-se como lente analítica o quadro conceitual Social-Ecological Sistems (SES) framework (MCGINNIS; OSTROM, 2014).

\section{COGESTÃO DE PROPRIEDAdES COMUNAIS E GESTÃo DE RECURSOS NATURAIS}

Como parte do processo e ideologia de desenvolvimento nacional, inicialmente alicerçado no agroextrativismo e mais tarde na industrialização, a ação governamental brasileira relacionada à gestão, uso, aproveitamento e controle dos recursos naturais se pautou em estratégias cunho punitivo centradas no governo central. Até o início dos anos 80, a política de gestão ambiental era focada em ações de comando e controle voltadas quase que exclusivamente para assegurar a produtividade e o desenvolvimento econômico e pouca atenção se deu ao uso sustentável dos recursos naturais (CÂMARA, 2013).

A partir de 1989, entretanto, com a criação do IBAMA (Instituto Brasileiro do Meio Ambiente e dos Recursos Naturais Renováveis) que assumiu a responsabilidade de formular, coordenar e executar a Política Nacional de Meio Ambiente (PNMA), a política de gestão ambiental assumiu um novo contorno. O instituto passou e ser o responsável pela execução do PNMA e a observar a preservação, conservação, uso racional, fiscalização, controle e fomento dos recursos naturais renováveis (BORDALO, 2007). A partir desse novo contorno da PNMA levada a cabo pelo IBAMA, a mobilização da sociedade para um envolvimento mais significativo no processo de tomada de decisão quanto a empreendimentos causadores de impactos ambientais mais expressivos (CÂMARA, 2013) passou a ser mais proeminente. $\mathrm{Na}$ mesma esteira de mudanças na estrutura para gestão ambiental nacional, a PNMA, "visando assegurar, no país, condições no desenvolvimento socioeconômico, aos interesses da segurança nacional e à proteção da dignidade da vida humana" (BORDALO, 2007), incluiu na concepção de gestão do meio ambiente, além dos recursos naturais, os aspectos culturais, sociais e econômicos.

A Constituição Brasileira de 1988 trouxe em seu capítulo 6, capítulo este específico sobre meio ambiente, há a inclusão do conceito (e processo) de cogestão dos recursos naturais. De acordo com os preceitos constitucionais, é dever do Estado Brasileiro, bem como dos atores sociais e mercado, a defesa e preservação do meio ambiente, cabendo ao Poder Público a 
implementação de políticas públicas voltadas à preservação e conservação do meio natural, desenvolvimento com base no uso racional dos recursos naturais e a garantia de qualidade de vida à população. Neste mesmo contexto, a sociedade civil assume o dever de controlar e, simultaneamente, avaliar a gestão ambiental a partir de sua participação nos processos decisórios. Há, assim, uma mudança no modelo de gestão ambiental governamental com maior participação da sociedade civil.

Com efeito, a participação da sociedade civil na gestão ambiental trouxe para o centro do debate a importância da participação das comunidades tradicionais para gestão das RESEX assumindo o papel de cogestoras. Ainda que esse modelo possa ser questionado pela grande influência de forças políticas e econômicas dominantes, a participação de comunidades tradicionais na gestão dos recursos naturais é um grande avanço em termos de gestão democrática de territórios.

A partir dos anos de 2000, com a aprovação da Lei n. ${ }^{\circ} 9.985$ que instituiu o SNUC, reclassificaram-se as categorias e regulamentou-se a criação e utilização de áreas protegidas destinadas à preservação dos ecossistemas naturais. Junto com esta reclassificação, o SNUC inovou em outros aspectos, tais como a instituição da participação social na criação e gestão de UC, a forma de tratamento de populações tradicionais que habitam áreas de proteção, além da alocação de recursos financeiros para a gestão dos territórios (BRASIL, 2000).

A cogestão, em particular relacionado à UC, pressupõe desafios, principalmente na efetivação de decisões deliberativas. Isso porque existem significativos conflitos entre os interesses individuais, coletivos, políticos, econômicos e sociais para a gestão e para o uso e aproveitamento dos recursos naturais. De acordo com Losekann (2012), há pelo menos três explicações para existência desses conflitos: primeiro, de um modo geral, existe uma grande dificuldade de priorizar as reivindicações ambientais quando estas contrariam os interesses econômicos, tanto locais quanto de outras escalas territoriais (regional e nacional). Segundo, o caráter consultivo e não vinculante das decisões advindas da participação das organizações civis na política ambiental. Isto se dá pelo fato de inexistir um instrumento legal compulsório para implementação das decisões pelo poder público. Terceiro, há baixa qualidade das deliberações realizadas no âmbito dos conselhos, sobretudo pelo desconhecimento da política ambiental. 
As UC regulamentadas pelo SNUC são consideradas como "bem de uso comum" (BRASIL, 1988). Estas se caracterizam por serem de livre acesso e de propriedade comum (OSTROM, 1990; HARDIN, 1968) o que leva, segundo Olson (1965) e Hardin (1968), a possibilidades de serem sobre exploradas.

De fato, há na literatura pelo menos três perspectivas analíticas sobre a utilização e gestão de recursos de acesso comum: a Lógica da Ação Coletiva (OLSON, 1965), A Tragédia dos Comuns (HARDIN, 1968) e a Teoria Common Poll Resource (OSTROM, 1990). Na primeira perspectiva, estatuída por Olson (1965), membros de um grupo com objetivos comuns não atuam voluntariamente para alcançar os interesses do grupo, mesmo que eles pudessem viver numa situação melhor quando este objetivo fosse alcançado. Isto aconteceria, segundo o autor, somente se o número de indivíduos do grupo fosse muito pequeno, ou se houvesse coerção ou qualquer outro estratagema especial que os levassem a agir em prol do interesse comum. Na perspectiva de Hardin (1968), a liberdade em relação ao uso dos recursos comuns gera a ruína de todos. Para evitar a tragédia dos comuns, segundo o autor, estes deveriam ser privatizados ou definidos como propriedades públicas - direitos de acesso e uso concedidos. Ostrom (1990), por sua vez, apresenta uma perspectiva totalmente diferenciada. Segundo Ostrom (1990), que analisou as regras e mecanismos que disciplinam a exploração do conjunto de recursos comuns por parte dos grupos utilizadores, as soluções eficazes e sustentáveis para proteger os recursos naturais são estabelecidas e implementadas pelos próprios usuários dos recursos, o que denota a importância da participação e cogestão no processo. Nas três lógicas de análise para a gestão de recursos comuns (OLSON, 1965; HARDIN, 1968; OSTROM, 1990), os conceitos de ação coletiva e cooperação estão inseridos como determinantes para os resultados.

Common Pool Resources (CPR) ou Recursos Comuns possuem duas características (McKEAN; OSTROM, 2011). Primeiro, há dificuldade para o desenvolvimento de instrumentos de exclusão dos potenciais beneficiários, demandando custos para as soluções dessas dificuldades. Isto implica em possibilidade de uso predatório, caso não haja incentivo para a preservação e manejo dos recursos. Segundo, unidades de recursos exploradas por um indivíduo não estarão mais disponíveis para outros. Em outros termos, são subtraíveis ou concorrentes no consumo, e, assim, exauridos. Dessa forma, a gestão dos recursos comuns necessariamente permeia pela estrutura institucional, ou seja, regras e mecanismos que 
disciplinam a exploração do conjunto dos recursos comuns (OSTROM, 1990). Soluções eficazes e sustentáveis para proteger os sistemas socioecológicos (que incluem os recursos naturais) perpassam, então, por regras (formais e informais) estabelecidas (OSTROM, 1990).

A gestão dos recursos comuns traz em seu bojo uma estrutura bastante complexa. Ao mesmo tempo em que os recursos são necessários para todos enquanto fonte de rendimentos e meios produtivos para o subsistema econômico; e, condição fundamental para qualidade de vida humana dentro do subsistema social; há a necessidade de seu uso de forma sustentável para manutenção do subsistema ecológico (SIMÕES; MACEDO; BABO, 2011). O sucesso da gestão dos recursos comuns está, então, relacionado a uma governança eficaz por pequenos grupos de usuários desses recursos. Esses pequenos grupos interagem com base em um conjunto de regras comuns envoltas por instituições em distintas escalas, além de aceite e respeito destas pelos grupos (SIMÕES; MACEDO; BABO, 2011).

\section{COGESTÃO EM UNIDADES DE CONSERVAÇÃO SOB A TEORIA DOS COMUNS}

Dentre as várias características que marcam uma RESEX está a de abrigar populações tradicionais. Estas enquanto grupos constituídos e interessados na gestão do território devem fazer parte do conselho gestor da UC. O conselho gestor deliberativo possui a competência de aprovar ações empregadas na unidade, acompanhar a elaboração, implementação e revisão do plano de manejo da UC, e buscar a compatibilização dos interesses dos diversos grupos sociais relacionados à unidade (BRASIL, 2015).

O caráter deliberativo do conselho gestor de uma RESEX, composto por representantes de diversos grupos da sociedade, incluindo a população tradicional, e de órgãos públicos, pressupõe a cogestão em nível operacional para a coprodução do território enquanto bem público. Todavia, apesar de ser preconizado o caráter deliberativo dos conselhos, pareceres oficiais tem apontado a predominância do seu caráter consultivo. Em outros termos, os conselhos gestores não tem se apresentado efetivos como espaço local de manifestação de opinião sobre assuntos diversos relacionados à gestão da biodiversidade. Há uma predominância de consulta e de aconselhamento, sem poder para deliberação ou decisão (MACHADO, COSTA, VILANI, 2012). 
Não obstante, com relação a experiências de gestão participativa em inúmeras regiões metropolitanas do mundo, Pitteri et al (2012) mostram que pode-se obter sucesso e alcançar objetivos em diversos contextos organizacionais independentemente das formações históricas ou aspectos culturais, orientações políticas ou pela sua importância econômica no contexto o globalizado. A gestão participativa aproxima diversos segmentos do governo e pode contribuir para que a sociedade adquira empowerment e exerça cidadania (PITTERI et al, 2012). A gestão participativa é um importante mecanismo de aproximação dos atores sociais, seja na relação estado-sociedade civil, estado-mercado, sociedade civil-mercado e estado-mercado-sociedade civil e abre espaços para a implantação de modelos de cogestão.

A cogestão pode ser entendida como a criação de uma arena formal de cooperação (CARLSSON; BERKES, 2003). É um processo complexo, uma vez que os atores sociais não são unos, mas partes distintas que apresentam diferentes interesses, devendo, dessas forma, elaborar um consenso mínimo entre estes (CARLSSON; BERKES, 2003). Existe o desafio de superar o distanciamento entre desejos e necessidades das comunidades locais em relação às decisões tomadas pelo poder público, tendo em vista as especificidades locais.

As iniciativas de governos locais sugerem um processo de reconstrução do Estado brasileiro, já marcado pela presença de parcerias entre Estado, sociedade civil e setor privado (FARAH, 2001). A parceria pode ser entendida como um canal para a construção da cogestão. Porém, há o questionamento se os conselhos gestores são capazes de representar efetivamente mudanças no ambiente institucional para a gestão dos territórios, tendo em vista o desafio da questão da conservação da biodiversidade e seu uso sustentável em contraposição ao modelo de ocupação antrópica, estruturas econômicas e práticas sociais arraigadas historicamente por um viés de desenvolvimento em que prevalece a exploração dos recursos naturais em um grau maior do que sua reposição (MACHADO; COSTA; VILANI, 2012).

Juridicamente, o Conselho Deliberativo de uma RESEX é presidido pelo órgão responsável por sua administração, o ICMbio, e é assim constituído: representantes de órgãos públicos, de organizações da sociedade civil e das populações tradicionais residentes na área (BRASIL, 2000).

Destaca-se que os órgãos ambientais possuem $100 \%$ da participação, visto que presidem os Conselhos Gestores das UC (MACHADO; COSTA; VILANI, 2012). Outrossim, as comunidades tradicionais podem explorar os recursos para sustento econômico, mas o poder público mantém papéis significativos de supervisão, monitoramento e avaliação da utilização 
dos recursos florestais (CRONKLETON; PULHIN; SAIGAL, 2012). Destaca-se, entretanto, que por meio dos conselhos deliberativos das RESEX e RDS, são previstos para as comunidades tradicionais existentes na UC o poder de decisão sobre gestão e, ao mesmo tempo, a possibilidade de deliberar sobre seus interesses, desde que estas estejam representadas por organizações da sociedade civil. Dentro desse contexto, a cogestão é um instrumento potencialmente promissor para a conservação de florestas e melhoria da qualidade de vida. Todavia, na prática, as estratégias e ações adotadas pelo poder público muitas vezes criam sistemas de cogestão defeituosos, comprometendo sua efetividade e limitando seu impacto (CRONKLETON; PULHIN; SAIGAL, 2012).

De fato, a questão da gestão coletiva (cogestão) de recursos comuns é discutida na literatura nacional e internacional em diversos contextos institucionais por meio da IAD e SES Framework e foca-se predominantemente no contexto biofísico e na interação com a comunidade (CAÑETE; CAÑETE, 2013. SCHMITZ; MOTA; SILVA JÚNIOR, 2009; BARBOSA; MARIN, 2010) e sobre atributos e regras de uso (SILVA FILHO et al, 2009. YU et al, 2014. CALDASSO, 2013).

Cañete \& Cañete (2013) fazem uma análise de como no Parque Nacional no Cabo Orange, localizado na costa do Amapá, tem se ordenado política e ambientalmente em relação à exploração dos recursos pesqueiros (comuns). Apesar dos Parques Nacionais pertencerem à categoria de UC de proteção integral, que não permite a presença humana ou exploração de seus recursos, a partir da pressão da demanda internacional e nacional de pescado, o Estado, na figura do ICMBio e outros atores e agentes sociais, se articulam para que haja um consenso e equilíbrio no uso desses recursos naturais. Assim, acordos pesqueiros foram estruturados com a Colônia de Pescadores, ICMbio, e pescadores artesanais, e se mostram como uma estratégia e alternativa exitosa no controle de manejo de recursos pesqueiros e gestão de conflitos socioambientais (CAÑETE; CAÑETE, 2013).

Schmitz, Mota \& Júnior (2009), por sua vez, analisam a gestão coletiva de bens comuns no extrativismo da mangaba no nordeste brasileiro e destacam o acesso aos recursos, arranjos institucionais e conflitos sociais entre os atores envolvidos. Os autores mostram a existência de remanescentes de mangabeiras bem conservados a partir da cogestão.

Silva Filho et al (2009) apresentam uma "análise política" do gerenciamento do meio ambiente em uma região metropolitana brasileira. Utilizam o IAD Framework e identificam a 
ação em forma de rede para a gestão de problemas específicos locais. Identificam, também, uma interação entre os atores do sistema do meio ambiente e atores do novo sistema de recursos hídricos, sendo este uma peça fundamental no caso da poluição hídrica da Região Metropolitana.

Yu et al (2014) mostram a transformação das instituições de gestão de recursos no âmbito da globalização por meio do caso das florestas comunitárias Songgye na Coreia do Sul. Os autores exploram os fatores que explicam a persistência da cooperação na utilização de recursos comuns por via de mudanças contextuais. Os autores mostram dois tipos de transformação: as cooperativas e as não cooperativas. Em ambas, os custos de transação associados ao tamanho do grupo e à diversidade da rede, segundo os autores, afetam a transformação. Detectou-se que SES com tamanhos menores e maior diversidade de rede podem organizar melhor as transformações de cooperação quando o sistema existente torna-se insustentável.

\section{METODOLOGIA APLICADA PARA ENTENDER A COGESTÃO DE RECURSOS COMUNS}

Dado o arcabouço teórico sobre a cogestão, traçou-se uma metodologia para entender a cogestão em uma Unidade de Conservação. Buscou-se a compreensão da cogestão como um modelo de gestão para um sistema socioecológico baseado no extrativismo. Para tal, utilizouse como lente analítica da cogestão o SES framework (MCGINNIS; OSTROM, 2014).

Utilizou-se como unidade de análise a comunidade tradicional São José do Abacatal Turé, pertencente a RESEX Terra Grande do Pracuúba, localizada no município de Curralinho, estado do Pará. Admitiu-se como conceito de população tradicional a definição de Diegues (2001): "populações indígenas, ribeirinhas, extrativistas, de pescadores artesanais, portadores de uma outra cultura [...], de seus mitos próprios e de relações com o mundo natural distintas das existentes nas sociedades urbano-industriais".

Destaque-se que foi realizado um recorte no quadro conceitual do SES Framework (MCGINNIS; OSTROM, 2014) e focou-se, neste estudo, apenas no "Sistema de Governança. Para tal, utilizou-se as evidencias e técnicas de pesquisa constantes no Quadro 1:

Quadro 1 - Análise do "Sistema de Governança" 


\begin{tabular}{|c|c|c|c|}
\hline $\begin{array}{l}\text { Variável } \\
\text { de } \\
\text { Primeiro }\end{array}$ & Variável de Segundo Nível & Evidências & $\begin{array}{c}\text { Técnicas de } \\
\text { Pesquisa }\end{array}$ \\
\hline 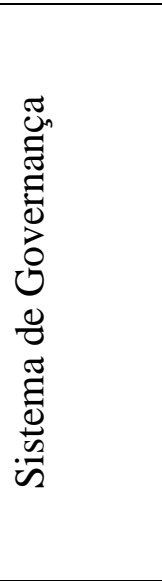 & $\begin{array}{l}\text { G } 1 \text { - Organizações } \\
\text { Governamentais } \\
\text { G2 - Organizações Não } \\
\text { Governamentais } \\
\text { G3 - Estrutura de Redes } \\
\text { G4 - Sistemas de Direito de } \\
\text { Propriedade } \\
\text { G5 - Regras Formais e } \\
\text { Informais } \\
\text { G6 - Monitoramento do } \\
\text { Cumprimento das Regras }\end{array}$ & $\begin{array}{l}\text { ICMBio, IBAMA, Conselho } \\
\text { Gestor } \\
\text { Associação de Moradores, } \\
\text { Colônia de Pescadores } \\
\text { Fiscalização de Pesca e } \\
\text { Desmatamento } \\
\text { Acordo de Uso do Território } \\
\text { e Plano de Manejo } \\
\text { Acordos e instrumentos } \\
\text { legais } \\
\text { Acordo de Gestão }\end{array}$ & $\begin{array}{l}\text { Entrevistas } \\
\text { Semiestruturadas }\end{array}$ \\
\hline
\end{tabular}
Fonte: Adaptado de (MCGINNIS; OSTROM, 2014).

No contexto apresentado, considerou-se a Comunidade São José do Abacatal Turé como um sistema socioecológico que influencia a totalidade do sistema socioecológico da RESEX Terra Grande do Pracuúba que engloba os recursos comuns ali existentes: atmosfera, as águas interiores, superficiais e subterrâneas, os estuários, o mar territorial, o solo, o subsolo, os elementos da biosfera, a fauna e a flora (BRASIL, 2000).

Os sistemas socioecológicos são dinâmicos, mudam continuamente em resposta a pressões internas e externas (SCHÜTER et al., 2014). No contexto da RESEX Terra Grande do Pracuúba, buscou-se a compreensão das interações ocasionadas pelas pressões internas e externas e de que forma impulsionam essa dinâmica para o desenvolvimento de estratégias de gestão sustentável, contempladas na cogestão da RESEX.

Para obtenção de evidências (Quadro 1) foram utilizadas pesquisa documental, entrevistas semiestruturadas e observação (YIN, 2005). As entrevistas semiestruturadas foram realizadas com informantes-chave (líder comunitário, representante da associação de moradores da Comunidade São José do Abacatal, Turé, professora educação infantil da comunidade, duas mulheres presentes na comunidade mesmo antes da regulamentação da RESEX e presidente da Colônia de Pescadores Z37, em Curralinho). Efetuou-se, também, análise documental em que foram apreciados os "Acordo de Gestão", "Acordos de Uso do Território" e "Acordo de pesca".

Para análise, definiu-se a cogestão em dois vieses, forte ou faca, seguindo o que propõe Williams \& Tai (2016). A cogestão forte foi definida como àquela com multinível de 
colaboração e processos multiescalares de fortalecimento institucional que proporcionam benefícios socioeconômicos para as comunidades locais (WILLIAMS; TAI, 2016). A iniciativa cogestão fraca foi definida como àquela que possui estruturas de governação fracas e redes limitadas para fortalecer a cogestão da UC (WILLIAMS; TAI, 2016). A cogestão fraca não consegue manter a auto-organização e outros processos críticos e não consegue fornecer benefícios socioeconômicos para as comunidades locais (WILLIAMS; TAI, 2016).

\section{A COGESTÃo DE RECURSOS COMUNS NA RESEX TERRA GRANDE DO PRACUÚBA}

A RESEX Terra Grande do Pracuúba foi criada em 2006, nos municípios de Curralinho e São Sebastião da Boa Vista (PA). Tem-se nesta reserva 23 comunidades e aproximadamente 660 famílias. As famílias ali existentes exploram a madeira, a pesca, a caça e o roçado para sua subsistência. A única forma de acesso à RESEX é por via fluvial. Muitas famílias replantam o açaí (escasso em muitas áreas devido ao corte indiscriminado para obtenção do palmito), mesmo sem muita orientação, pois é um produto economicamente valorizado (ICMbio, 2015).

Empiricamente, constatou-se que a criação da RESEX Terra Grande do Pracuúba foi uma demanda da própria população tradicional. Ou seja, a criação da RESEX emergiu dentro de uma lógica bottom-up, sem imposição pelo poder público (ICMBio, 2015). Destaca-se que emergiu a partir da cooperação entre as comunidades para dirimir os problemas de superexploração dos recursos comuns.

O "Sistema de direito de propriedade" é de Uso e a posse e o uso das áreas dentro dos limites da RESEX Terra Grande do Pracuúba são regulados por contrato e concessão de uso da terra (ICMBio, 2015). A regulamentação se dá por meio do Acordo de uso do Território, Plano de Manejo.

O Plano de Manejo é o documento técnico mediante o qual, com fundamento nos objetivos de gerais de uma UC, se estabelece o seu zoneamento e as normas que devem presidir o uso da área e o manejo dos recursos naturais. Todavia, a RESEX Terra Grande do Pracuúba não possui Plano de Manejo formal (ICMBio, 2015). Existe evidência de que o ICMBio e outros atores e agentes sociais podem se articular para que haja consenso e equilíbrio no uso de recursos naturais (CAÑETE; CAÑETE, 2012). Porém, observou-se a existência de conflitos resultantes do uso inadequado dos recursos naturais na RESEX que comprometem a integridade ecológica e provocam forte desarticulação dos moradores e comunidades. Tais conflitos 
dificultam a organização social (ICM-Bio, 2015), limitam os resultados da cogestão em nível de decisão e até mesmo de execução, principalmente no âmbito da colaboração.

A ação em forma de rede é um instrumento para a gestão de problemas específicos locais (SILVA FILHO et al. (2009). Porém, a pesquisa de campo exploratória mostra que na Comunidade São José do Abacatal - Turé há um descenso em relação à implementação da RESEX Terra Grande do Pracuúba. Este descenso enfraquece o sistema de governança. De acordo com um entrevistado, a implementação da RESEX obteve o apoio de apenas 12 moradores. Isso talvez explique porque essa Comunidade não possui representante no Conselho Gestor, apesar da existência de uma associação, a Associação de moradores "Mãe da RESEX" que, em tese, os representam. Há o desejo de alguns moradores de criar uma associação de moradores da Comunidade São José do Abacatal - Turé para efetivamente representá-los, ao invés de cooperar e interagir com a Associação de moradores "Mãe da RESEX”. Assim, há uma limitação na cogestão, uma vez que esta pressupõe a cooperação voluntária (BRUDNEY; ENGLAND, 1983).

Sistemas socioecológicos com tamanhos de grupo menores e maior diversidade de rede podem organizar melhor as transformações de cooperação quando o sistema existente torna-se insustentável (YU et al, 2014). Porém, observou-se que a falta de cooperação e articulação em redes e de consenso na Comunidade São José do Abacatal Turé da RESEX Terra Grande do Pracuúba implica um limite para a cogestão e posteriormente coprodução. De acordo com Carlsson; Berkes (2003), o consenso é um elemento fundamental para a cogestão e coprodução. Nesse contexto, pela falta de um processo mais aproximado entre os atores, há falta de conhecimento até dos procedimentos burocráticos necessários para formalização de uma “Associação", o que tornou um impedimento até para obtenção do Cadastro Nacional de Pessoa Jurídica (CNPJ) (Entrevistado 2).

Foi identificado pelo menos duas obras, de iniciativa do Governo Federal, paradas e inacabadas: uma escola e um posto de saúde. "A casa dos professores foi uma conquista para a comunidade e resultado da luta de um professor que solicitou a doação de madeira ilegal apreendida". "Nas outras comunidades existem escolas, posto de saúde e as casas possuem fossa séptica" (Entrevistado 2). Essas situações demonstram a fragilidade das articulações, limitando a cogestão como meio de influência na formulação de políticas públicas por meio do conselho gestor. 
A participação da comunidade no conselho gestor se dá por meio da representação a partir das pessoas formalmente indicadas pela associação dos moradores. Dessa forma, por um lado, não há representação desta comunidade no conselho gestor da RESEX Terra Grande do Pracuúba e, por outro lado, não há consenso com os demais representantes para cooperação ao alcance do bem comum para a RESEX, "sendo priorizados nas deliberações do Conselho Gestor os interesses de outras comunidades que possuem representação" (Entrevistado 2).

Ao invés de uma lógica de ação coletiva voltada para a cooperação (MCGINNIS; OSTROM, 2014), há sobreposição do interesse individual sobre o coletivo (HARDIN, 1968). No entanto, observou-se que essa lógica é voltada para uma racionalidade individual, porém, relacionada ao grupo familiar e não para o conjunto da comunidade, ou seja, em detrimento do sistema socioecológico:

a) "Se eu não explorar o açaí nativo ou a madeira que existe no meu quintal, quem vai sustentar essas crianças?” (Entrevistado 3).

b) “O IBAMA veio e proibiu a madeira. E agora, como vamos viver?” (Entrevistado 4).

c) "Eu não considero o açaí nativo como recurso comum, é meu, está no meu quintal" (Entrevistado 5).

Destaca-se que o interesse individual se relaciona ao bem estar do grupo familiar em um contexto de pressão para alcance da subsistência em condições de pobreza extrema, alto índice de gravidez na adolescência, condições precárias de saneamento básico, inexistência de água potável e fossas sépticas, escola em condições precárias, inexistência de posto de saúde, dependência econômica de produtos da floresta e difícil acesso. Essa lógica pode explicar a venda de parte ou da totalidade do capital natural relevante sem contribuir de volta para bemestar coletivo da comunidade (YU et al, 2014) caracterizado nesse caso específico, pela exploração ilegal de madeira.

Constatou-se pelo menos dois grupos apresentando opiniões divergentes sobre a criação da RESEX: Os que concordam com a criação da RESEX que entendem a necessidade de compatibilizar a conservação da natureza com o uso sustentável dos recursos naturais e os que não concordam. Não foi observada a coprodução, haja vista que o envolvimento da comunidade é um componente central (BIER, et al, 2010). Mais especificamente, quanto à fiscalização do desmatamento, identificou-se a exploração ilegal de madeira e serraria dentro na Comunidade. Destaca-se que a exploração vegetal ilegal de madeira "também parte de indivíduo pertencente à comunidade tradicional da RESEX" (Entrevistado 2) e modifica o sistema socioecológico, comprometendo a sustentabilidade. Portanto, em mais este exemplo, há a sobreposição dos interesses individuais sobre o coletivo. 
De acordo com Pennington (2012), as comunidades onde a população tem um compromisso moral com as regras em operação são mais susceptíveis de garantir a execução do que aqueles que não possuem uma identificação moral com as regras pertinentes. Quanto às "Regras Formais e Informais" e ao "Monitoramento do Cumprimento das Regras", identificouse que a RESEX Terra Grande do Pracuúba possui formalizado um Acordo de Gestão (ICMbio, 2013) que contem regras para moradia, ocupação de terreno, exploração de produtos florestais madeireiros e não madeireiros, cultivo em roça, uso do fogo, criação de animais, caça, pesca, manejo de lixo, embarcações, e também de responsabilidade pelo cumprimento do acordo. Existia uma prática de exploração de madeira anterior à criação da RESEX Terra Grande do Pracuúba. Posteriormente, foi formalizado o Acordo de Gestão que permite o extrativismo vegetal (madeira) apenas para uso familiar e comunitário - por exemplo, na construção de casas, barcos e igrejas. Os entrevistados demonstraram não possuir clareza quanto ao objetivo da RESEX nem o compromisso legal com as regras estabelecidas pelo Acordo de Gestão, haja vista que existe uma forte ideia de que é certa a exploração de madeira. A comercialização exige plano de manejo florestal comunitário (ICMbio 2013), podendo explicar a exploração ilegal de madeira (Figura 2).

Numa cultura tradicional e homogênea e numa comunidade relativamente estável, onde as pessoas têm fortes laços sociais e de reputação e um compromisso com o desenvolvimento em longo prazo, é menos provável de permitir a entrada de free-riding do que em uma comunidade em transformação sem forte senso de local ou identificação cultural (PENNINGTON, 2012). Observou-se, no entanto, que na RESEX Terra Grande do Pracuúba, especificamente na Comunidade São José do Abacatal-Turé, que o free-riding, o oportunista, é caracterizado como o atravessador de farinha, morador da comunidade que compra a farinha mais barata dos moradores da comunidade, sem alternativa por não possuírem meios de escoamento da produção e vende com um preço muito superior em Curralinho. Pelo conjunto dessas informações, percebe-se claramente a existência de uma cogestão fraca na RESEX Terra Grande do Pracuúba e na Comunidade São José do Abacatal-Turé.

\section{CONSIDERAÇÕES FINAIS}


O estudo mostrou que a cogestão ainda é um modelo limitadamente aplicado para a gestão sustentável em reserva extrativista. Embora a cogestão possa se apresentar como uma inovação social para a gestão de territórios, trata-se de um conceito ainda em construção e experimentação na prática, sobretudo em áreas de preservação ambiental e Unidades de Conservação.

Especificamente no caso da Comunidade São José do Abacatal-Turé, como parte da RESEX Terra Grande do Pracuúba, a iniciativa de cogestão é fraca. Identificou-se uma estrutura de gestão com redes pouco extensas e limitadas, o que dificulta a efetivação de um dos escopos da cogestão: o diálogo e a participação nos diversos níveis de decisão. Isto faz com que haja a predominância de uma organização sobre outra no processo de gestão do território. No caso específico analisado, o ICMBio enquanto órgão estatal que regulamenta a estrutura de gestão assume a cogestão enquanto discurso; entretanto, na prática, assume o papel de principal responsável para a gestão da RESEX por meio do controle indireto e pela imposição externa de regras e regulamentos.

Como consequência, a participação de comunidades tradicionais não se efetiva em termos de representação, predominando, assim, os interesses dos atores públicos, o que gera conflitos e impossibilita a coprodução por meio da cogestão. No caso da RESEX analisada, cabe ao ICMbio a implementação ou o indeferimento das ações deliberadas Conselho Gestor. Há, ainda, o agravante de que o presidente deste colegiado é o representante do ICMBio.

$\mathrm{Na}$ aplicação, os resultados quanto à operacionalização da cogestão em nível comunitário mostram que também há limitações. Ora porque a comunidade não demonstrou um pertencimento e construção coletiva do processo de compatibilizar a conservação da natureza com o uso sustentável dos recursos naturais da RESEX, o que caracteriza relações históricas estabelecidas intra-comunidade; ora porque não há articulação da comunidade em redes ou parcerias para sua melhor representação no Conselho Gestor Deliberativo da RESEX. Esta pesquisa limita-se por não ter havido oportunidade de participar de reuniões do Conselho Gestor, restringindo-se à pesquisa de campo, entrevistas abertas, observação e análise de conteúdo de documentos oficiais.

Por fim, destaque-se que a fiscalização para pressões como desmatamento não é eficaz nem em âmbito governamental nem no âmbito da própria comunidade, existindo o extrativismo ilegal dentro da RESEX Terra Grande do Pracuúba, Comunidade São José do Abacatal Turé. 


\section{REFERÊNCIAS}

BARBOSA, M. J. S. et al. Relatório analítico do território do Marajó. Belém: UFPA 2012.

BIER, G. A. et al. Sociedade, empresa e governo: uma experiência de implementação de um novo paradigma de democracia participativa. Cadernos EBAPE. BR, Rio de Janeiro, v. 8, n. 4, Dez. 2010.

BRASIL. Lei $n^{\circ}$ 9.985, de 18 de Julho de 2000. Regulamenta o artigo 225, § $1^{\circ}$, incisos I, II, III e VII da Constituição Federal, institui o Sistema Nacional de Unidades de Conservação da Natureza e dá outras providências. Ministério do Meio Ambiente, Brasília. Disponível em: <http://www.mma.gov.br/port/conama/legiabre.cfm?codlegi=322>.Acesso em: 15 jun. 2015.

Instituto Chico Mendes de Conservação da Biodiversidade. Resex Verde para Sempre Combate ao Desmatamento. ICMBio, Brasília: 2015. Disponível em: <http://www.icmbio.gov.br/portal/comunicacao/noticias/20geral/3861resexverdeparasempree macoescontinuasdecombateadesmatamento.html>. Acesso em: 2 ago. 2015.

BRUDNEY, J. L.; ENGLAND, R. E. Toward a Definition of the Coproduction Concept. Public Administration Review, v. 43, n. 1, Jan./Feb.1983, p. 59-65. Disponível em: <http://www.jstor.org/stable/975300>. Acesso em: 24 fev. 2015.

CARLSSON, L.; BERKES, F. "Co-Management Across Levels of Organization: Concepts and Methodological Implications." Presented at "Politics of the Commons: Articulating Development and Strengthening Local Practices", Chiang Mai, Thailand, July 11-14, 2003. Disponível em: <http://dlc.dlib.indiana.edu/archive/00001133/00/Lars_Carlsson.pdf>. Acesso em: 21 fev. 2015.

CANÇADO, A. C.; PEREIRA, J. R.; TENÓRIO, F. G. Gestão social: epistemologia de um paradigma. 2. ed. Curitiba: CRV, 2015.

CAÑETE, U. M. R; CAÑETE, V. R. Recursos Comuns, Conflito e Território: Cenários de Pesca em uma Área Transfronteiriça Amazônica-Brasil/Guayana. In: X ENCONTRO DA ECOECO. Anais... Vitória, ES, 2013.

CRONKLETON, Peter, PULHIN, Juan M, SAIGAL, Sushil. Co-management in Community Forestry: How the Partial Devolution of Management Rights Creates Challenges for Forest Communities. Conservation and Society, v. 10, n. 2, p. 91-102, 2012.

DIEGUES, A. C. S. O Mito moderno da natureza intocada. 3.ed. São Paulo: Hucitec, 2001. FENNY, David et al. A tragédia dos comuns 22 anos depois. In: DIEGUES, A. C. S.; MOREIRA, A.C. (Orgs). Espaços e recursos naturais de uso comum. São Paulo: NUPAUB/USP, 2011. 
FARAH, M. F. S. Parcerias, novos arranjos institucionais e políticas públicas no nível local de governo. Revista de Administração Pública, v. 35, jan./fev.2001.

HOFFMAN, D. R.; IRELAND, D. Elinor Ostrom, Institutions and Governance of the Global Commons. Disponível em:<https://clubofromeagm2013.files.wordpress.com/2013/08/ostrom_institutions_commons _draft_2013_july_22.docx.>. Acesso em: 21 fev. 2015.

LOSEKANN, Cristiana. Participação da sociedade civil na política ambiental do Governo Lula. Ambiente \& Sociedade, São Paulo, v. 15, n. 1, jan./abr. 2012.

MACHADO, C. J. S; COSTA, D. R. T. R.; VILANI, R. M. A análise do princípio da participação social na organização federal dos conselhos de unidades gestores de conservação e mosaicos: realidades e desafios. Revista Brasileira de Gestão e Desenvolvimento Regional, Taubaté, SP, v. 8, n. 3, p. 50-75, set. /dez. 2012,

MCKEAN, M. A; OSTROM, E. Regimes de propriedade comum em florestas: somente uma relíquia do passado? In: DIEGUES, Antonio Carlos; MOREIRA, André de Castro C. Espaços e recursos naturais de uso comum. São Paulo: Napaub-USP, 2011.

MCGINNIS, Michael D.; OSTROM, Elinor. Social-ecological system framework: initial changes and continuing challenges. Ecology and Society 19(2): 30, 2014. Disponível em: <http://dx.doi.org/10.5751/ES-06387-190230>. Acessso em:15 nov. 2015.

; OSTROM, E. IAD and SES Dynamic Flows: Introducing the Program in Institutional Analysis of Social-Ecological Systems (PIASES) Framework. In: $13^{\circ}$ ECONOMICS OF INFRASTRUCTURES CONFERENCE. Anais... Delft, Netherlands, april, p. 27-28, 2010.

OLSON, M. A lógica da ação coletiva: os benefícios públicos e uma teoria dos grupos sociais. Tradução Fábio Fernandez. São Paulo: Editora da USP: 2011.

OSTROM, E. Governing the Commons: the evolution of institutions for collective action. Indiana University: University Press. Cambridge, 1990.

Institutional Analysis and Development: Elements of the Framework in Historical Perspective." In Historical Developments and Theoretical Approaches in Sociology, ed. Charles Crothers, in Encyclopedia of Life Support Systems (EOLSS). Oxford, UK: EOLSS Publishers, 2010.

PITTERI, S. et al. Gestão Participativa em Áreas Metropolitanas: Formação de Organizações Estratégicas para o Desenvolvimento Urbano e Inclusão Social. Revista de Gestão Pública: Práticas e Desafios, Recife, v. III, n. 6, dez. 2012.

PENNINGTON, M. Elinor Ostrom, common-pool resources and the classical liberal tradition. In: OSTROM, E. The Future of the Commons. IEA: The Institute of Economic Affairs, London: 2012. Disponível em: < http://www.iea.org.uk/sites/default/files/publications/files 
/IEA\%20Future\%20of\%20the\%20Commons\%20web\%2029-1.10.12.pdf>. Acesso em: 04 out. 2015.

SCHMITZ, H. MOTA, D. M da. SILVA JÚNIOR, J. F. da. Gestão coletiva de bens comuns no extrativismo da mangaba no nordeste do Brasil. Ambiente \& Sociedade, Campinas, SP, v. XII, n. 2. p. 273-292. jul.-dez. 2009.

SCHLÜTER, M., J. Hinkel, P. W. G. Bots, and R. Arlinghaus. 2014. Application of the SES framework for model-based analysis of the dynamics of social-ecological systems. Ecology and Society. Disponível em: <http://dx.doi.org/10.5751/ES-05782-190136>. Acesso em: 25 nov. 2015.

SILVA FILHO, J. C. L. et al. Gestão Ambiental Regional: Usando o IAD Framework de Elinor Ostrom na "Análise Política" da Gestão Ambiental da Região Metropolitana de Porto Alegre. Organizações \& Sociedade, Salvador, v.16, n.51, p. 609-627, out./dez. 2009.

TARKO, V. Elinor Ostrom's life and Work. In: The Future of the Commons. IEA: The Institute of Economic Affairs, London: 2012. Disponível em: < http://www.iea.org.uk/sites /default/files/publications/files/IEA\%20Future\%20of\%20the\%20Commons\%20Web\%20291.10.12.pdf>. Acesso em: 04 out. 2015.

TEIXEIRA, D. R. et al. Descrição da Análise Quantitativa da Composição e Grau de Participação de Atores Públicos e Privados nos Conselhos de Unidades de Conservação e Mosaicos Federais segundo o Arcabouço Legal. In: V ENCONTRO DA ANPPAS, Anais.... Florianópolis, SC, out. 2010.

VASCONCELLOS, Mário; VASCONCELLOS, Ana Maria de A. State-Civil Society Partnership: issues for debate and new researches. Organizações \& Sociedade, v. 18, n.59, 2011.

YU, D., J. M. Anderies, D. Lee, and I. Perez. 2014. Transformation of resource management institutions under globalization: the case of songgye community forests in South Korea. Ecology and Society. Disponível em <http://dx.doi.org/10.5751/ES-06135-190202>. Acesso em: 20 out. 2015.

YIN. R. K. Estudo de caso: planejamento e métodos. 3.ed. Porto Alegre: Bookman, 2005.

WILLIAMS, K.W.; TAI, H.-S.A Multi-Tier Social-Ecological System Analysis of Protected Areas Co-Management in Belize. Sustainability 2016. 